\title{
Emotional Intelligence and Depression Among Hospital Nurses of Tehran University of Medical Sciences
}

\author{
Maryam Shabany ${ }^{1}$ and Mahsa Ghajarzadeh ${ }^{1,2,{ }^{*}}$ \\ ${ }^{1}$ Brain and Spinal Cord Injury Research Center, Neuroscience Institute, Tehran University of Medical Sciences, Tehran, Iran \\ ${ }^{2}$ Universal Council of Epidemiology (UCE), Universal Scientific Education and Research Network (USERN), Tehran, Iran \\ "Corresponding author: Brain and Spinal Cord Injury Research Center, Neuroscience Institute, Tehran University of Medical Sciences, and Universal Council of Epidemiology \\ (UCE), Universal Scientific Education and Research Network (USERN), Tehran, Iran. Tel: +98-2166581560, Email: m.ghajarzadeh@gmail.com \\ Received 2018 April 28; Accepted 2018 July 25.
}

\begin{abstract}
Background: Emotional intelligence(EI) and depression are important issues that can affect the quality of nurse's work. Emotional intelligence is also an indicator of mental and physical health condition.

Objectives: This study was designed to evaluate emotional intelligence and depression of hospital nurses working at Tehran University of Medical Sciences in Iran.

Methods: In this cross sectional study, 113 hospital nurses of TUMS at different wards were enrolled. They filled the Persian version of the baron emotional quotient inventory (EQ-i) and beck depression inventory (BDI).

Results: Mean age of participants was 25 years and 58\% were male. Mean BDI and EI scores except independence and responsibility were not significantly different between male and female cases. Mean EI and its subscales were similar in different wards except emotional self-awareness. The correlation coefficient between BDI and total EI was $\mathrm{r}=0.2$ and $\mathrm{P}=0.008$, and the correlation coefficient between age and total EI was $\mathrm{r}=-0.2, \mathrm{P}=0.02$.

Conclusions: According to the results, depression evaluation and emotional intelligence improvement should be considered in Iranian nurses, who work at university associated hospitals.
\end{abstract}

Keywords: Depression, Emotional Intelligence, Nurses, Iran

\section{Background}

One of the most important individuals in the health care system are nurses, which comprise of the largest single professional group (1)

Between 2004 and 2006, health care providers were ranked third for depressive episodes (2). Researches have shown that nurses experience psychological problems, such as stress and depression $(3,4)$. Low mood, loss of concentration, disability in performing mental or interpersonal tasks well, and less output are consequences of depression in individuals (5-7).

Depression in hospital nurses impacts their professional function, quality of care, and also their coworkers (2). Therefore, considering this issue is essential.

Evaluation of EI could help identify cases, who are at risk of developing depression $(8,9)$.

Emotional intelligence is defined as the ability of screening and explaining one's own and other's experi- ences and feelings, to differentiate them, and apply essential information to determine thoughts and actions $(10,11)$.

Furthermore, EI is important in definition, perception, understanding, and regulation of emotions (12).

It has been suggested that higher EI indicates better mental and physical health as well as better control of stress (13). Emotional intelligence for nurses is considered as a protective factor against stress (14). As nurses face different difficult situations in their work life, such as work overload, night shift, death of the patient, problems with colleagues, staff shortage or lack of support, higher EI will help them overcome these problems (15).

\section{Objectives}

Therefore, as nurses should communicate with patients in different situations and concentrate on their work to provide better care, this study was designed to evaluate 
depression and EI and their association with related factors in hospital nurses of Tehran University of Medical Sciences.

\section{Methods}

\subsection{Sampling}

This was a cross sectional study, which was conducted at Tehran University of Medical Sciences (TUMS) between August 2015 and August 2016. One hundred and thirty hospital nurses of TUMS in different wards, such as emergency medicine, internal medicine, and surgery, were randomly selected by means of random numbers (generated numbers by computers).

\subsection{Materials}

The participants were asked to fill the Persian version of beck depression inventory and the baron emotional quotient inventory (EQ-i), which have been proven to be valid and reliable $(16,17)$.

Emotional quotient inventory (EQ-i) includes 90 questions. It is a self-report questionnaire, which includes five categories and 15 scales. The five categories are intrapersonal (self-regard, emotional self- awareness, assertiveness, independence, and self actualization), interpersonal empathy, social responsibility, and interpersonal relationship, stress management (stress tolerance and impulse control), adaptability (reality testing, flexibility and problem solving), and general mood scale (optimism and happiness). Each question is based on a five-point Likert scale scoring system ranging from five to one (completely agree: five to completely disagree: one). The total score is the sum of all questions scores. A higher score is considered as higher emotional intelligence.

Beck depression inventory (BDI) should be answered according to the patient's feelings in the last week, including 21 questions. The answer to each question is scored from 0 to 3 to determine the person's depression level. Individuals with scores between 0 and 9 are not considered as depressed, scores between 10 and 18 indicate mild to moderate depression, scores between 19 and 29 indicate moderate to severe depression, and scores between 30 and 63 correspond to severe depression.

\subsection{Data Analysis}

Data was analyzed by the SPSS software version 20 (SPSS Inc., Chicago, IL, USA). Data were presented as mean \pm standard deviation (SD) for continuous or frequencies for categorical variables. Continuous variables were compared by means of independent sample t-test. P-values of less than 0.05 were considered significant.

\subsection{Ethical Considerations}

All participants filled informed consent forms before study entrance.

\section{Results}

One hundred and thirteen nurses from 130 filled the questionnaires, and the response rate was $87 \%$. Basic characteristics of enrolled cases are summarized in Table 1. Fifty-eight participants were not depressed (51.3\%), 29 (25.7\%) had mild depression, 20(17.7\%) had moderate and 6 (5.3\%) were severely depressed.

\begin{tabular}{lc}
\hline Table 1. Baseline Characteristics of the Participants & \\
\hline Variables & Values \\
\hline Age, mean (SD) & $25.3(0.5)$ \\
\hline Sex, No. (\%) & $66(58.4)$ \\
\hline Male & $47(41.5)$ \\
\hline Female & $15.8(0.08)$ \\
\hline Education level, mean (SD) ${ }^{\mathrm{a}}$ & \\
\hline Ward, No. (\%) & $40(35.4)$ \\
\hline Internal medicine & $40(35.4)$ \\
\hline Emergency & $33(29.2)$ \\
\hline
\end{tabular}

${ }^{a}$ Based on the number of years of schooling.

The correlation coefficient between BDI and total EI was 0.2 , P was 0.008 , indicating weak statistical significance. Also, the correlation coefficient between age and total EI was significant statistically yet weak and inverse $(\mathrm{r}=$ $-0.2, \mathrm{P}=0.01)$.

Moreover, description of different EI items are summarized in Table 2.

Mean BDI and EI scores, except independence and responsibility, were not significantly different between male and female cases (Table 3 ).

Mean EI and its subscales were similar in different ward's attendance, except emotional self-awareness (Table 4). 


\begin{tabular}{|lc|}
\hline Table 2. Descriptive of Different EI Items & \\
\hline Subscales & Mean $($ SD $)$ \\
\hline Problem solving & $14(0.2)$ \\
\hline Happiness & $14.5(0.3)$ \\
\hline Independence & $15.1(0.3)$ \\
\hline Stress tolerance & $17.2(0.3)$ \\
\hline Self-actualization & $14.9(0.3)$ \\
\hline Emotional self-awareness & $15(0.2)$ \\
\hline Reality testing & $17.3(0.3)$ \\
\hline Interpersonal relationship & $13.4(0.3)$ \\
\hline Optimism & $14.3(0.2)$ \\
\hline Self-regard & $13.9(0.2)$ \\
\hline Impulse control & $18.4(0.4)$ \\
\hline Flexibility & $17.3(0.2)$ \\
\hline Responsibility & $12.6(0.3)$ \\
\hline Empathy & $12.3(0.3)$ \\
\hline Assertiveness & $17(0.3)$ \\
\hline
\end{tabular}

\begin{tabular}{lccc}
\hline Table 3. Comparison Between Mean & BDI and EI Items in Different Sex Groups \\
\hline Subscale & Male & Female & P-Value \\
\hline Total BDI & $11.4 \pm 1.2$ & $11.8 \pm 1.5$ & 0.8 \\
\hline Problem solving & $13.9 \pm 0.3$ & $14.1 \pm 0.4$ & 0.6 \\
\hline Happiness & $14.1 \pm 0.4$ & $15.2 \pm 0.5$ & 0.1 \\
\hline Independence & $15.8 \pm 0.4$ & $14.3 \pm 0.3$ & 0.01 \\
\hline Stress tolerance & $16.9 \pm 0.4$ & $17.7 \pm 0.5$ & 0.2 \\
\hline Self-actualization & $15 \pm 0.4$ & $14.7 \pm 0.4$ & 0.7 \\
\hline Emotional self-awareness & $15 \pm 0.3$ & $15.1 \pm 0.4$ & 0.8 \\
\hline Reality testing & $17.4 \pm 0.4$ & $17.1 \pm 0.5$ & 0.6 \\
\hline Interpersonal relationship & $13.4 \pm 0.4$ & $13.5 \pm 0.4$ & 0.8 \\
\hline Optimism & $14.1 \pm 0.3$ & $14.5 \pm 0.4$ & 0.5 \\
\hline Self-regard & $13.8 \pm 0.3$ & $14.1 \pm 0.3$ & 0.6 \\
\hline Impulse control & $19 \pm 0.6$ & $17.7 \pm 0.6$ & 0.1 \\
\hline Flexibility & $17.3 \pm 0.3$ & $17.3 \pm 0.4$ & 0.8 \\
\hline Responsibility & $13.2 \pm 0.4$ & $11.7 \pm 0.4$ & 0.02 \\
\hline Empathy & $12.1 \pm 0.4$ & $12.7 \pm 0.4$ & 0.3 \\
\hline Assertiveness & $16.7 \pm 0.4$ & $17.5 \pm 0.4$ & 0.1 \\
\hline Total EI & $228.1 \pm 36.4$ & $227.8 \pm 30.5$ & 0.9 \\
\hline
\end{tabular}

\section{Discussion}

The results of present study showed that mean EI and BDI were not significantly different between gender groups as well as different wards. The results also showed that mean responsibility and independence scores were significantly different between different genders. These items were higher in males.

However, Naghavi and Redzuan in their study reported that EI in females was higher than males (15). In a previous study by the current authors, mean responsibility score was significantly different between male and female medical residents (10). Although not significant, this study investigated that surgery residents had higher EI scores (10).

This study also found a weak association between EI and BDI as well as EI and age.

In a previous study conducted by Namdar et al. in Tabriz (18), mean EI score of nursing students was 332 while this score was 228 in the current study. Similar to the current findings, mean EI scores were not significantly different between males and females.

In contrast to the current results, higher EI score of college students was reported by Brackett et al. (19).

Barkhordari and Rostambeygi assessed EI of nursing students of Yazd university and reported mean EI of 331 and no difference between the scores of males and females (20).

Haghani et al. evaluated EI in Isfahan medical students, and reported significantly higher responsibility score in male participants, which is compatible with the current results (21).

In the current study, the researchers did not find a strong association between EI and age (-0.2, P = 0.01), similar to the author's previous study $(\mathrm{r}=-0.04, \mathrm{P}=0.7)(10)$. This finding was in agreement with other studies $(18,20)$.

Evaluating EI of people is of interest for psychologists and educators (19). Team activities, functioning, academic success, and life enjoyment are positively associated with EI $(18,22)$.

Therefore, evaluating EI of nurses, who are in contact with patients, is important.

In a previous study, Beauvais et al. reported a positive association between emotional intelligence and nursing performance, which could indicate that for people, who make decisions, take action, and perform well, higher EI is necessary (23).

It should be considered that in the real world, nurses face life and death decisions. For better nursing performance, improved decision making and problem solving is essential (24).

On the other hand, nurses should have empathy for patients and manage their emotions. Therefore, improving EI will help them provide better care (25).

Moreover, in the present study, nearly half of the partic- 


\begin{tabular}{|c|c|c|c|c|}
\hline Subscale & Internal Medicine & Surgery & Emergency Medicine & P-Value \\
\hline Problem solving & $14.1 \pm 2.8$ & $13.6 \pm 3.2$ & $14.3 \pm 3.3$ & 0.6 \\
\hline Happiness & $15 \pm 3.7$ & $13.9 \pm 4.1$ & $14.8 \pm 4.3$ & 0.4 \\
\hline Independence & $16 \pm 2.4$ & $14.6 \pm 3.7$ & $14.9 \pm 3.3$ & 0.1 \\
\hline Stress tolerance & $17.7 \pm 2.7$ & $17.1 \pm 4.6$ & $16.7 \pm 3$ & 0.5 \\
\hline Self-actualization & $15.2 \pm 3$ & $14.5 \pm 4$ & $14.9 \pm 3.2$ & 0.6 \\
\hline Emotional self-awareness & $15.9 \pm 2.5$ & $14.3 \pm 3.3$ & $14.8 \pm 2.2$ & 0.03 \\
\hline Reality testing & $17.1 \pm 3$ & $17.7 \pm 4.6$ & $17.1 \pm 2.7$ & 0.7 \\
\hline Interpersonal relationship & $13.8 \pm 3.1$ & $12.6 \pm 3.8$ & $14.1 \pm 3.5$ & 0.1 \\
\hline Optimism & $15.1 \pm 2.7$ & $13.6 \pm 3.5$ & $14.1 \pm 2.8$ & 0.1 \\
\hline Self-regard & $14 \pm 2.9$ & $13.5 \pm 2.6$ & $14.3 \pm 3.3$ & 0.4 \\
\hline Impulse control & $18.9 \pm 4.3$ & $18.4 \pm 5.6$ & $17.8 \pm 4.5$ & 0.6 \\
\hline Flexibility & $17.9 \pm 2.6$ & $17.1 \pm 3.5$ & $16.9 \pm 2.9$ & 0.3 \\
\hline Responsibility & $12.8 \pm 3.4$ & $11.8 \pm 3.5$ & $13.3 \pm 3.9$ & 0.1 \\
\hline Empathy & $12.8 \pm 3.1$ & $11.7 \pm 3.6$ & $12.6 \pm 3.3$ & 0.3 \\
\hline Assertiveness & $17.2 \pm 2.1$ & $16.9 \pm 3.8$ & $17.1 \pm 3.6$ & 0.9 \\
\hline Total & $233.8 \pm 25.9$ & $221.8 \pm 38.1$ & $228.5 \pm 33.9$ & 0.2 \\
\hline
\end{tabular}

ipants had depression. Letvak et al. demonstrated depressive symptoms rate as $18 \%$ in employed nurses (2).

This study had some limitations. First, it was conducted at university affiliated wards and second, the authors did not include nurses of all wards.

\subsection{Conclusions}

According to the results, depression evaluation and emotional intelligence improvement should be considered in Iranian nurses, who work at university associated hospitals.

\section{References}

1. Perry L, Lamont S, Brunero S, Gallagher R, Duffield C. The mental health of nurses in acute teaching hospital settings: a cross-sectional survey. BMC Nurs. 2015;14:15. doi: 10.1186/s12912-015-0068-8. [PubMed: 25904820]. [PubMed Central: PMC4405850].

2. Letvak S, Ruhm CJ, McCoy T. Depression in hospital-employed nurses. Clin Nurse Spec. 2012;26(3):177-82. doi: 10.1097/NUR.ob013e3182503efo. [PubMed: 22504476].

3. Gershon RR, Stone PW, Zeltser M, Faucett J, MacDavitt K, Chou SS. Organizational climate and nurse health outcomes in the United States: a systematic review. Ind Health. 2007;45(5):622-36. [PubMed: 18057805].

4. Tajvar A, Saraji GN, Ghanbarnejad A, Omidi L, Hosseini SS, Abadi AS. Occupational stress and mental health among nurses in a medical intensive care unit of a general hospital in Bandar Abbas in 2013. Electron Physician. 2015;7(3):1108-13. doi: 10.14661/2015.1108-1113. [PubMed: 26388976]. [PubMed Central: PMC4574696].

5. Jacob IG. Depression's impact on safety. Occup Health Saf. 2006;75(10):32-34, 38 passim. [PubMed: 17059055].
6. Lerner D, Henke RM. What does research tell us about depression, job performance, and work productivity? J Occup Environ Med. 2008;50(4):401-10. doi: 10.1097/JOM.0b013e31816bae50. [PubMed: 18404013].

7. Wang J, Schmitz N, Smailes E, Sareen J, Patten S. Workplace characteristics, depression, and health-related presenteeism in a general population sample. J Occup Environ Med. 2010;52(8):836-42. doi: 10.1097/JOM.0b013e3181ed3d80. [PubMed: 20657301].

8. Downey LA, Johnston PJ, Hansen K, Schembri R, Stough C, Tuckwell $\mathrm{V}$, et al. The relationship between emotional intelligence and depression in a clinical sample. Eur J Psychiat. 2008;22(2). doi: 10.4321/s021361632008000200005.

9. Ciarrochi J, Deane FP, Anderson S. Emotional intelligence moderates the relationship between stress and mental health. Pers Indiv Differ. 2002;32(2):197-209. doi: 10.1016/s0191-8869(01)00012-5.

10. Ghajarzadeh M, Mohammadifar M. Emotional intelligence of medical residents of Tehran University of Medical Sciences. Acta Med Iran. 2013;51(3):185-8. [PubMed: 23605604].

11. Elam C, Stratton TD, Andrykowski MA. Measuring the emotional intelligence of medical school matriculants. Acad Med. 2001;76(5):507-8. [PubMed: 11346542].

12. Salovey P, Sluyter DJ. Emotional Development and Emotional Intelligence: Educational Implications. University of Michigan: Basic Books; 1997.

13. Mikolajczak M, Luminet O, Menil C. Predicting resistance to stress: incremental validity of trait emotional intelligence over alexithymia and optimism. Psicothema. 2006;18 Suppl:79-88. [PubMed: 17295962].

14. Augusto Landa JM, Lopez-Zafra E, Berrios Martos MP, Aguilar-Luzon Mdel C. The relationship between emotional intelligence, occupational stress and health in nurses: a questionnaire survey. Int $J$ Nurs Stud. 2008;45(6):888-901. doi: 10.1016/j.ijnurstu.2007.03.005. [PubMed: 17509597]. 
15. Naghavi F, Redzuan M. The relationship between gender and emotional intelligence. World Appli Sci J. 2011;15(4):555-61.

16. Ghassemzadeh H, Mojtabai R, Karamghadiri N, Ebrahimkhani N. Psychometric properties of a Persian-language version of the Beck Depression Inventory-Second edition: BDI-II-PERSIAN. Depress Anxiety. 2005;21(4):185-92. doi: 10.1002/da.20070. [PubMed:16075452].

17. Samuei R. Standardization of BarOn emotional intelligence test. Tehran: Sina Research Institution on behavioral sciences. 2003.

18. Namdar H, Sahebihagh M, Ebrahimi H, Rahmani A. Assessing emotional intelligence and its relationship with demographic factors of nursing students. Iran J Nurs Midwifery Res. 2009;13(4).

19. Brackett MA, Mayer JD, Warner RM. Emotional intelligence and its relation to everyday behaviour. Pers Indiv Differ. 2004;36(6):1387-402. doi:10.1016/s0191-8869(03)00236-8.

20. Barkhordari M, Rostambeygi P. Emotional intelligence in nursing students. J Adv Med Educ Professionalism. 2013;1(2):46-50.

21. Haghani F, Aminian B, Kamali F, Jamshidian S. Critical Thinking Skills and Their Relationship with Emotional Intelligence in Medical Students of Introductory Clinical Medicine (ICM) Course in Isfahan University of Medical Sciences. Iran J Med Educ. 2011;10(5).

22. Guleryuz G, Guney S, Aydin EM, Asan O. The mediating effect of job satisfaction between emotional intelligence and organisational commitment of nurses: a questionnaire survey. Int J Nurs Stud. 2008;45(11):1625-35. doi: 10.1016/j.ijnurstu.2008.02.004. [PubMed: 18394625].

23. Beauvais AM, Brady N, O'Shea ER, Griffin MTQ. Emotional intelligence and nursing performance among nursing students. Nurse Educ Today. 2011;31(4):396-401. doi:10.1016/j.nedt.2010.07.013.

24. McQueen AC. Emotional intelligence in nursing work. J Adv Nurs. 2004;47(1):101-8. doi: 10.1111/j.1365-2648.2004.03069.x. [PubMed: 15186473]

25. Evans D, Allen H. Emotional intelligence: its role in training. Nurs Times. 2002;98(27):41-2. [PubMed: 12123168]. 